\title{
The Biosimilar Nocebo Effect? A Systematic Review of Double-Blinded Versus Open-Label Studies
}

\author{
Johlee S. Odinet, PharmD, BCPS; Chelsea E. Day, BS; Jennifer L. Cruz, PharmD, BCPS;
} and Gregory A. Heindel, PharmD, BCPS

\begin{abstract}
BACKGROUND: Several authors have hypothesized that adverse drug events (ADEs) upon switching from reference biologics to biosimilar products are related to the nocebo effect. However, a thorough and current review of the existing literature has not been conducted.

OBJECTIVE: To evaluate if patient and/or physician knowledge of a switch from a reference biologic product to a biosimilar product was associated with an increase in ADEs likely to be susceptible to the nocebo effect.

METHODS: Studies reporting efficacy and safety outcomes of a switch from a reference product to a biosimilar product were reviewed. Biologics with FDA-approved biosimilars in the United States were considered for review, including adalimumab, bevacizumab, etanercept, and infliximab. Studies were identified by searching controlled vocabulary (e.g., MeSH terms) and keywords within MEDLINE (via PubMed) and Embase. Descriptive statistics were used to quantify subjective and objective complications in doubleblinded and single-blinded or open-label studies.
\end{abstract}

RESULTS: Thirty-one trials including 3,271 patients were reviewed in the full analysis. Median discontinuation rates for any reason were $14.3 \%$ (range $=0.0-33.3$ ) in open-label studies compared with $6.95 \%$ (range $=5.2$ 11.0 ) in double-blinded studies. Discontinuation rates for ADEs were $5.6 \%$ ( range $=0.0-24.2$ ) in open-label studies versus $3.1 \%$ (range $=2.0-5.2$ ) in double-blinded studies, suggesting the nocebo effect does affect biosimilar adoption. Subgroup analyses of antidrug antibody (ADA) development and infusion reactions were similar between infliximab open-label and doubleblinded studies. Discontinuation rates for any reason, for ADEs, and for lack of efficacy were generally higher in infliximab open-label trials compared with double-blinded trials. Etanercept biosimilar discontinuation rates for any reason were similar between study designs; however, incidences of injection site reactions and discontinuation rates for ADEs were higher in double-blinded compared with open-label study designs.

CONCLUSIONS: Current evidence is insufficient to confirm a biosimilar nocebo effect, although higher discontinuation rates in infliximab biosimilar open-label studies support this theory. Further studies are needed to evaluate the existence of a biosimilar nocebo effect.

J Manag Care Spec Pharm. 2018;24(10):952-59

Copyright $\odot 2018$, Academy of Managed Care Pharmacy. All rights reserved.

\section{What is already known about this subject}

The nocebo effect has been defined as negative expectations that lead to negative consequences following an inert exposure. It has been hypothesized that adverse drug events (ADEs) of biosimilar switches are related to the nocebo effect without significant comparisons between open-label versus blinded outcomes.

\section{What this study adds}

By comparing subjective and objective outcomes in open-label and blinded trial designs, this comprehensive review evaluated the possibility of a nocebo effect when switching from originator to biosimilar products.

Current evidence is insufficient to confirm a biosimilar nocebo effect, although higher discontinuation rates in infliximab biosimilar open-label studies support this theory.

The nocebo effect may further inhibit biosimilar adoption, especially in light of previously established provider discomfort with switching to a biosimilar product.

I n 2010, the Biologics Price Competition and Innovation (BPCI) Act created an abbreviated approval pathway, 351(k), for biosimilars. Biosimilars are biological products approved by the U.S. Food and Drug Administration (FDA) that have demonstrated a high degree of similarity and a lack of clinically relevant differences compared with a reference (brandname) FDA-approved biologic product. ${ }^{1}$ Biosimilar products may present opportunities for substantial cost savings for health systems if used in the place of higher-cost reference biologic products. ${ }^{2,3}$ By 2020, approximately $\$ 100$ billion in cost per year of biologic products will lose patent exclusivity, which exemplifies the large cost savings potential. ${ }^{4}$ Indeed, the National Health Service of the United Kingdom reported a cumulative cost savings of greater than 38 million pounds over a 2-year period, solely from the introduction of infliximab and etanercept biosimilars. ${ }^{5}$ However, the use of biosimilar products in the United States has remained relatively slow, compared with Europe, since the passage of the BPCI Act. ${ }^{6}$

Many challenges to the widespread adoption of biosimilars have been reported in the United States, including variable cost, insurance coverage, and reimbursement; aggressive reference product exclusivity contracting; lack of multiple biosimilar products for one reference product; and provider concerns over the strength of evidence supporting safety and efficacy of biosimilars. Clinical concerns seem especially prevalent when considering switching maintenance therapy to a biosimilar product in a currently stable patient. ${ }^{6-8}$ Some authors have also suggested that the nocebo effect may further hinder the use of biosimilar products. ${ }^{9,10}$ 
The Biosimilar Nocebo Effect? A Systematic Review of Double-Blinded Versus Open-Label Studies

TABLE 1 Baseline Characteristics of Infliximab Biosimilar Switching Studies $20-47$

\begin{tabular}{|c|c|c|c|c|c|c|}
\hline Author (Year) & Design & $\begin{array}{l}\text { Biosimilar } \\
\text { Product }\end{array}$ & Indication & $\begin{array}{l}\text { Switched } \\
\text { Population }\end{array}$ & $\begin{array}{c}\text { Baseline ADA } \\
\text { n/N (\%) }\end{array}$ & $\begin{array}{c}\text { Follow-up } \\
\text { (Weeks) }\end{array}$ \\
\hline \multicolumn{7}{|l|}{ Double-blinded studies } \\
\hline Smolen et al. (2017)20 & MC PRO RCT & Renflexis & RA & 94 & - & 78 \\
\hline Jorgensen et al. (2017)21 & MC PRO RCT & Inflectra & IBD, PsO, SpA, RA, PsA & 241 & - & 52 \\
\hline \multicolumn{7}{|l|}{ Open-label studies } \\
\hline Park et al. $(2017)^{22}$ & MC PRO OBS & Inflectra & AS & 86 & $22 / 86 \quad(25.6)^{\mathrm{a}}$ & 48 \\
\hline Jung et al. $(2015)^{23}$ & MC RET OBS & Inflectra & IBD & 36 & - & 30 \\
\hline Kang et al. (2015)24 & SC RET OBS & Inflectra & IBD & 9 & - & 48 \\
\hline Park et al. $(2015)^{25}$ & MC RET OBS & Inflectra & IBD & 60 & - & 30 \\
\hline Hlavaty et al. (2016) 26 & SC RET OBS & Inflectra & IBD & 12 & - & 44 \\
\hline Schmitz et al. (2017) 27 & MC PRO OBS & Inflectra & IBD & 133 & $8 / 133 \quad(6.0)$ & 52 \\
\hline Eberl et al. $(2017)^{28}$ & SC PRO OBS & Inflectra & IBD & 62 & $1 / 62 \quad(7.6)$ & 16 \\
\hline Fiorino et al. (2017)29 & SC PRO OBS & Inflectra & IBD & 18 & - & 62 \\
\hline Smits et al. $(2017)^{30}$ & SC PRO OBS & Inflectra & IBD & 83 & $5 / 83 \quad(6.0)$ & 52 \\
\hline Arguelles-Arias et al. (2017)31 & SC PRO OBS & Inflectra & IBD & 98 & - & 52 \\
\hline Razanskaite et al. (2017) 32 & SC PRO OBS & Inflectra & IBD & 143 & $28 / 143 \quad(19.6)$ & 52 \\
\hline Buer et al. $(2017)^{33}$ & SC PRO OBS & Inflectra & IBD & 143 & $2 / 143 \quad(1.4)$ & 26 \\
\hline Fiorino et al. $(2017)^{34}$ & MC PRO OBS & Inflectra & IBD & 97 & - & 26.4 \\
\hline Kolar et al. (2017) 35 & SC PRO OBS & Inflectra & IBD & 74 & $7 / 74 \quad(9.5)$ & 56 \\
\hline Smits et al. $(2016)^{36}$ & SC PRO OBS & Inflectra & IBD & 83 & $5 / 83 \quad(6.0)$ & 52 \\
\hline Kang et al. (2018) 37 & SC PRO OBS & Inflectra & IBD & 38 & $3 / 38 \quad(7.9)$ & 52 \\
\hline Nikiphorou et al. (2015)38 & SC PRO OBS & Inflectra & RA & 39 & $3 / 39 \quad(7.7)$ & 47.7 \\
\hline Tanaka et al. $(2017)^{39}$ & SC PRO OBS & Inflectra & RA & 33 & - & 80 \\
\hline Yoo et al. $(2017)^{40}$ & MC PRO OBS & Inflectra & RA & 144 & $69 / 144 \quad(47.9)^{b}$ & 40 \\
\hline Glintborg et al. (2017) 41 & MC PRO OBS & Inflectra & RA & 802 & - & 59 \\
\hline Benucci et al. (2017) 42 & MC PRO OBS & Inflectra & SpA & 41 & $27 / 41 \quad(65.9)$ & 26 \\
\hline Vergara-Dangond et al. (2017) 43 & SC RET OBS & Inflectra & RA, PsA, AS & 7 & - & 34.7 \\
\hline Holroyd et al. (2018) ${ }^{44}$ & SC RET OBS & Inflectra & RA, AS, PsA, EnA & 59 & - & 51.6 \\
\hline Avouac et al. (2017) 45 & SC PRO OBS & Inflectra & RA, SpA, IBD & 260 & - & 33.9 \\
\hline Schmitz et al. (2017) ${ }^{46}$ & SC PRO OBS & Inflectra & RA, PsA, AS, SpA, PsO, UC & 27 & - & 52 \\
\hline Abdalla et al. (2017) ${ }^{47}$ & SC PRO OBS & Inflectra & RA, AS, PsA, IBD & 34 & - & 68.5 \\
\hline \multicolumn{7}{|c|}{ 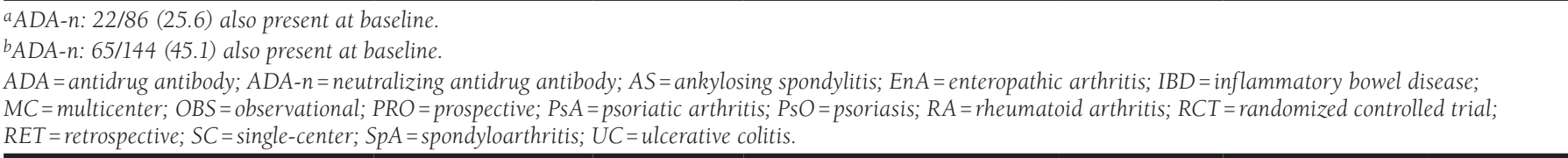 } \\
\hline
\end{tabular}

The nocebo effect does not have a single consensus definition, but it may broadly be described as negative expectations that lead to negative consequences. In other words, it is the negative equivalent to the placebo effect. ${ }^{9,11}$ Social observations, perceived dose, verbal suggestions of symptoms, and baseline symptom expectations are the strongest factors that may increase the risks of experiencing nocebo effects. ${ }^{12}$ An increased incidence of adverse drug events (ADEs) related to the nocebo effect has previously been reported for several medications, including 3-hydroxy-3-methylglutaryl coenzyme A reductase inhibitors (statins), finasteride, beta blockers, caffeine, and antiepileptics. ${ }^{13-17}$

Surveys demonstrate physician hesitancy surrounding switching practices, potentially as a result of general knowledge gaps about biosimilar products. For example, in a survey, greater than $95 \%$ of rheumatologist respondents stated that they would prefer prescribing a biologic reference product over its biosimilar product. ${ }^{7}$ Up to $41 \%$ of patient respondents also reported reluctance to accept biosimilars due to potential side effects or long-term problems. ${ }^{8}$ If this so-called nocebo effect is indeed present, it may further inhibit biosimilar uptake, especially in light of established provider discomfort and negative expectations.

The Anglo-Scandinavian Cardiac Outcomes Trial was one of the first and largest studies to document an increase in ADEs from the nocebo effect. In the first phase of the trial, patients were randomized in a double-blinded fashion to atorvastatin or placebo. During the open-label extension phase, all patients were offered the option to receive atorvastatin therapy. The incidence of definite or probable statin-associated muscle 
TABLE 2 Infliximab Biosimilar Switching Discontinuations and ADEs 20-47 $^{2}$

\begin{tabular}{|c|c|c|c|c|c|}
\hline Author (Year) & $\begin{array}{c}\text { Infusion Reaction } \\
\mathrm{n} / \mathrm{N}(\%)\end{array}$ & $\begin{array}{l}\text { ADA Development } \\
\text { n/N (\%) }\end{array}$ & $\begin{array}{c}\text { Discontinuation, } \\
\text { Any } \\
\mathrm{n} / \mathrm{N}(\%)\end{array}$ & $\begin{array}{c}\text { Discontinuation, } \\
\text { ADE } \\
\text { n/N (\%) }\end{array}$ & $\begin{array}{l}\text { Discontinuation, } \\
\text { Lack of Efficacy } \\
\text { n/N (\%) }\end{array}$ \\
\hline \multicolumn{6}{|l|}{ Double-blinded studies } \\
\hline Smolen et al. (2017)20 & - & $13 / 94(13.8)$ & $6 / 94 \quad(6.4)$ & $3 / 94 \quad(3.2)$ & - \\
\hline Jorgensen et al. (2017)21 & $5 / 241 \quad(2.0)$ & $30 / 241 \quad(12.4)$ & $18 / 241 \quad(7.5)$ & $6 / 241 \quad(2.5)$ & $3 / 241 \quad(1.2)$ \\
\hline \multicolumn{6}{|l|}{ Open-label studies } \\
\hline Park et al. $(2017)^{22}$ & $6 / 86 \quad(7.0)$ & $28 / 86(32.6)^{a}$ & \multirow{2}{*}{$\begin{array}{ll}9 / 86 & (10.5) \\
5 / 36 & (13.9)\end{array}$} & $4 / 86 \quad(4.7)$ & - \\
\hline Jung et al. $(2015)^{23}$ & - & - & & $1 / 36 \quad(2.8)$ & $3 / 36 \quad(8.3)$ \\
\hline Kang et al. (2015)24 & - & - & - & $1 / 9 \quad(11.1)$ & $1 / 9(11.1)$ \\
\hline Park et al. $(2015)^{25}$ & $3 / 60 \quad(5.0)$ & & - & - & - \\
\hline Hlavaty et al. (2016)26 & $0 / 12 \quad(0.0)$ & - & $2 / 12(16.7)$ & $1 / 12 \quad(8.3)$ & $1 / 12 \quad(8.3)$ \\
\hline Schmitz et al. $(2017)^{27}$ & - & $3 / 133 \quad(2.3)$ & $35 / 133(26.3)$ & $13 / 133 \quad(9.8)$ & $12 / 133 \quad(9.0)$ \\
\hline Eberl et al. (2017)28 & $4 / 156 \quad(2.6)^{\mathrm{b}}$ & $2 / 62 \quad(3.2)$ & $0 / 62 \quad(0.0)$ & $0 / 62 \quad(0.0)$ & $0 / 62 \quad(0.0)$ \\
\hline Fiorino et al. (2017) 29 & $1 / 18 \quad(5.6)$ & $32 / 127(25.2)^{\mathrm{b}}$ & - & - & - \\
\hline Smits et al. (2017)30 & - & $2 / 83 \quad(2.4)$ & $15 / 83(18.1)$ & $5 / 83 \quad(6.0)$ & $2 / 83 \quad(2.4)$ \\
\hline Arguelles-Arias et al. (2017) ${ }^{31}$ & $2 / 98 \quad(2.0)$ & - & $5 / 98 \quad(5.1)$ & $6 / 98 \quad(6.1)$ & $2 / 98 \quad(2.0)$ \\
\hline Razanskaite et al. (2017)32 & $2 / 143 \quad(1.4)$ & 28/143 (19.6) & $41 / 143(28.7)$ & $13 / 143 \quad(9.1)$ & $16 / 143(11.2)$ \\
\hline Buer et al. $(2017)^{33}$ & $5 / 143 \quad(3.5)$ & $5 / 143 \quad(3.5)$ & $4 / 143 \quad(2.8)$ & $2 / 143 \quad(1.4)$ & - \\
\hline Fiorino et al. $(2017)^{34}$ & $7 / 97 \quad(7.2)$ & - & $5 / 97 \quad(5.2)$ & $\begin{array}{ll}3 / 97 & (3.1) \\
2 / 97 & (2.1)^{\mathrm{c}} \\
\end{array}$ & $0 / 94 \quad(0.0)$ \\
\hline Kolar et al. $(2017)^{35}$ & - & $4 / 74 \quad(5.4)$ & - & $2 / 74 \quad(2.7)$ & $2 / 74 \quad(2.7)$ \\
\hline Smits et al. $(2016)^{36}$ & - & $2 / 83 \quad(2.4)$ & $15 / 83(18.1)$ & $6 / 83 \quad(7.2)$ & - \\
\hline Kang et al. (2018) 37 & $0 / 38 \quad(0.0)$ & $4 / 38 \quad(10.5)$ & $1 / 38 \quad(2.6)$ & - & $1 / 38 \quad(2.6)$ \\
\hline Nikiphorou et al. $(2015)^{38}$ & - & - & $\begin{array}{rr}11 / 39 & (28.2) \\
3 / 39 & (7.7)^{\mathrm{d}} \\
\end{array}$ & $6 / 39 \quad(15.4)$ & - \\
\hline Tanaka et al. $(2017)^{39}$ & $4 / 33 \quad(12.1)$ & $16 / 33 \quad(48.5)$ & $11 / 33 \quad(33.3)$ & $8 / 33(24.2)$ & $2 / 33 \quad(6.1)$ \\
\hline Yoo et al. $(2017)^{40}$ & $4 / 144 \quad(2.8)$ & $84 / 144(58.3)^{e}$ & $16 / 144 \quad(11.1)$ & $8 / 144 \quad(5.6)$ & $1 / 144 \quad(0.7)$ \\
\hline Glintborg et al. (2017) $)^{41}$ & - & - & $132 / 802 \quad(16.5)$ & $37 / 802 \quad(4.6)$ & $71 / 802 \quad(8.9)$ \\
\hline Benucci et al. (2017) ${ }^{42}$ & - & $27 / 41 \quad(65.9)$ & - & $1 / 41 \quad(2.4)$ & - \\
\hline Vergara-Dangond et al. (2017) ${ }^{43}$ & - & - & - & $1 / 7 \quad(14.3)$ & - \\
\hline Holroyd et al. $(2018)^{44}$ & - & - & $8 / 59(13.6)$ & $4 / 59 \quad(6.8)$ & $4 / 59 \quad(6.8)$ \\
\hline Avouac et al. (2017) 45 & $1 / 260 \quad(0.4)$ & - & $59 / 260(22.7)$ & $1 / 260 \quad(0.4)$ & $47 / 260(18.1)$ \\
\hline Schmitz et al. (2017) 46 & - & $4 / 27 \quad(14.8)$ & $7 / 27(25.9)$ & - & $2 / 27 \quad(7.4)$ \\
\hline Abdalla et al. (2017) 47 & $1 / 34 \quad(2.9)$ & - & $5 / 34 \quad(14.7)$ & $1 / 34 \quad(2.9)$ & $2 / 34 \quad(5.9)$ \\
\hline
\end{tabular}

aADA-n: 25/86 (29.1).

${ }^{b}$ Reported as number of samples or infusions.

cDiscontinuation due to infusion reaction.

dDiscontinued due to ADA before switch.

'ADA-n: 64/144 (44.4).

$A D A=$ antidrug antibody; $A D A-n=$ neutralizing antidrug antibody; $A D E=$ adverse drug event.

symptoms (SAMS) was not different between the atorvastatin and placebo groups during the double-blinded period (hazard ratio $[\mathrm{HR}]=1.03 ; 95 \%$ confidence interval $[\mathrm{CI}]=0.88-1.21$ ). During the open-label extension phase, however, significantly more SAMS were reported in the group receiving atorvastatin compared with the atorvastatin nonusers ( $\mathrm{HR}=1.41 ; 95 \%$ $\mathrm{CI}=1.1-1.79$ ). This result indicated that the patients' definitive knowledge of receiving statin therapy, and the associated potential side effects, may have increased the incidence of ADEs. ${ }^{13}$

Indeed, the knowledge of the potential for negative effects may increase a patient's perception of ADEs. ${ }^{18}$ One study reported that patients who were educated about potential medication-related side effects experienced symptoms almost 4 times as often as patients who were not educated on these symptoms. ${ }^{15}$ Despite the evidence supporting a nocebo effect with traditional small-molecule medications, few studies have closely evaluated its presence in the context of biosimilar products. A recent open-label study of patients who were switched from the reference product to an infliximab biosimilar, CT-P13, revealed that the majority of treatment discontinuations were related to subjective ADEs, such as arthralgia, fatigue, pruritus, and myalgia. The authors suggested that these ADEs and subsequent treatment discontinuations were attributed to the 
The Biosimilar Nocebo Effect? A Systematic Review of Double-Blinded Versus Open-Label Studies

TABLE 3 Baseline Characteristics of Etanercept Biosimilar Switching Studies ${ }^{48-50}$

\begin{tabular}{|c|c|c|c|c|c|c|}
\hline Author (Year) & Design & $\begin{array}{l}\text { Biosimilar } \\
\text { Product }\end{array}$ & Indication & $\begin{array}{l}\text { Switched } \\
\text { Population }\end{array}$ & $\begin{array}{c}\text { Baseline ADA } \\
\text { n/N (\%) }\end{array}$ & $\begin{array}{l}\text { Follow-up } \\
\text { (Weeks) }\end{array}$ \\
\hline \multicolumn{7}{|l|}{ Double-blinded studies } \\
\hline Griffiths et al. (2017) 48 & MC PRO RCT & Erelzi & $\mathrm{PsO}$ & $\begin{array}{r}100^{\mathrm{a}} \\
96^{\mathrm{b}}\end{array}$ & - & 40 \\
\hline Gerdes et al. (2017) ${ }^{49}$ & MC PRO RCT & Erelzi & $\mathrm{PsO}$ & $196^{c}$ & - & 18 \\
\hline \multicolumn{7}{|l|}{ Open-label studies } \\
\hline Emery et al. (2017) 50 & MC PRO OBS & Brenzys & RA & 119 & - & 48 \\
\hline \multicolumn{7}{|c|}{$\begin{array}{l}\text { aPatients receiving GP2015 for period } 1 \text { then switched to etanercept } \rightarrow G P 2015 \rightarrow \text { etanercept, which continued into extension. } \\
\text { bPatients receiving etanercept for period } 1 \text { then switched to GP2015 } \rightarrow \text { etanercept } \rightarrow G P 2015 \text {, which continued into extension. } \\
\text { 'Includes patients from Griffiths et al. }(2017)^{48} \text { who were either switched from a reference to biosimilar or biosimilar to reference product. } \\
A D A=\text { antidrug antibody; } M C=\text { multicenter; } O B S=\text { observational; } P R O=\text { prospective; } P S O=\text { ssoriasis; } R A=\text { rheumatoid arthritis; } R C T=\text { randomized controlled trial. }\end{array}$} \\
\hline
\end{tabular}

nocebo effect and not related to the efficacy or safety of the biosimilar product. ${ }^{10}$ Similarly, a recent small observational study evaluated a nocebo-effect response defined as unexplained, undesirable therapeutic effects after a switch from a reference product to an infliximab biosimilar. ${ }^{19}$ An overall nocebo response rate of $12.8 \%(16 / 125)$ resulted, further suggesting a negative effect on patients' perceived disease burden.

A thorough and current review of the existing literature has not been conducted. We hypothesized that the incidence of subjective ADEs (e.g., patient discomfort) would be higher in openlabel biosimilar switching studies, as they would be more likely to be affected by a nocebo effect. Conversely, the incidence of objective ADEs (e.g., laboratory values) would remain consistent between open-label and double-blinded studies, as they would be less likely to be affected by a nocebo effect. We categorized ADEs as highly likely, intermediate, and unlikely to be affected by the nocebo effect. Discontinuation rates were considered as highly likely, infusion and injection site reactions as intermediate, and antidrug antibody (ADA) development as unlikely. Therefore, the objective of this review was to evaluate if patient and/or physician knowledge of a switch from a reference biologic product to a biosimilar product was associated with an increase in ADEs likely to be susceptible to the nocebo effect.

\section{Methods}

Studies reporting efficacy and safety outcomes of a switch from a reference product to a biosimilar product were reviewed. Primary literature that focused on FDA-approved biosimilars was considered for review, including adalimumab, bevacizumab, etanercept, and infliximab. Studies of filgrastim were excluded due to the generally low immunogenicity potential and low incidence of discontinuations related to ADEs. The research protocol and initial search was completed before FDA approval of trastuzumab-dkst, so it was not included in this review. Studies were identified by searching controlled vocabulary (e.g., MeSH terms) and keywords within MEDLINE (via PubMed) and Embase. The last search was conducted on
February 2, 2018. Search terms included infliximab, Remicade, Inflectra, infliximab-dyyb, CT-P13, Remsima, Renflexis, Flixabi, SB2, infliximab-abda, etanercept, Enbrel, Erelzi, etanercept-szzs, GP2015, adalimumab, Humira, Cyltezo, BI 695501, adalimumabadbm, ABP 501, Amjevita, adalimumab-atto, d2e7, bevacizumab, Avastin, Mvasi, ABP 215, bevacizumab-awwb, biosimilar, biosimilar agent, biosimilar pharmaceuticals, and biosimilar drug. No filters were applied to search results. Conference abstracts, posters, and non-English publications were excluded. Titles and abstracts were independently assessed for inclusion by 2 reviewers. Disagreements were resolved via consensus discussion.

A standardized data collection sheet was used to extract data from each trial, including study design, patient population, baseline characteristics, outcome measures, and duration of follow-up. Descriptive statistics were used to quantify results. Subjective and objective complications were compared between double-blinded and single-blinded or open-label studies.

\section{Results}

For inclusion in the review, 1,153 results were assessed: 591 for infliximab, 228 for adalimumab, 198 for etanercept, and 117 for bevacizumab. After removing duplicates and assessing relevance of outcome measures, 31 trials including 3,271 patients were reviewed in the full analysis. Only 1 relevant trial was identified that included a switch to adalimumab biosimilar products, so it was excluded from analysis. No relevant studies were identified for bevacizumab.

Of the 31 included trials, 28 involved switches from infliximab and 3 from etanercept to their biosimilar product counterparts. Trials were primarily conducted in the United States and United Kingdom. The most common indications for treatment were inflammatory bowel disease (IBD), rheumatoid arthritis (RA), and psoriasis (15, 6, and 2 studies, respectively). Six studies included multiple disease states. The median duration of follow-up after the switch to the biosimilar product was 48 weeks (range $=16-80$ weeks). A summary of trial design and baseline characteristics for infliximab and etanercept studies is 
TABLE 4 Etanercept Biosimilar Switching Discontinuations and ADEs ${ }^{48-50}$

\begin{tabular}{|c|c|c|c|c|c|}
\hline Author (Year) & $\begin{array}{c}\text { Injection Site Reaction } \\
\mathrm{n} / \mathrm{N}(\%)\end{array}$ & $\begin{array}{l}\text { ADA Development } \\
\text { n/N (\%) }\end{array}$ & $\begin{array}{c}\text { Discontinuation, } \\
\text { Any } \\
\text { n/N (\%) }\end{array}$ & $\begin{array}{c}\text { Discontinuation, } \\
\text { ADE } \\
\text { n/N (\%) }\end{array}$ & $\begin{array}{c}\text { Discontinuation, } \\
\text { Lack of Efficacy } \\
\text { n/N (\%) } \\
\end{array}$ \\
\hline \multicolumn{6}{|l|}{ Double-blinded studies } \\
\hline Griffiths et al. (2017) & - & $\begin{array}{ll}0 / 100^{\mathrm{b}} & (0.0) \\
1 / 96 & (1.0)^{\mathrm{c}} \\
\end{array}$ & $\begin{array}{cc}11 / 100 & (11.0)^{\mathrm{b}} \\
5 / 96 & (5.2)^{\mathrm{c}} \\
\end{array}$ & $\begin{array}{ll}2 / 100 & (2.0)^{\mathrm{b}} \\
5 / 96 & (5.2)^{\mathrm{c}} \\
\end{array}$ & $\begin{array}{c}2 / 100 \\
-\end{array}$ \\
\hline Gerdes et al. $(2017)^{49}$ & $72 / 196 \quad(36.7)$ & $0 / 196 \quad(0.0)$ & - & $6 / 196$ & - \\
\hline \multicolumn{6}{|l|}{ Open-label studies } \\
\hline Emery et al. (2017) 50 & $0 / 119 \quad(0.0)$ & $1 / 119 \quad(0.8)$ & $6 / 119 \quad(5.0)$ & $2 / 119$ & - \\
\hline $\begin{array}{l}{ }^{a} \text { Results reported after secon } \\
\text { betients receiving GP2015 } \\
\text { cPatients receiving etanercep } \\
\text { ADA = antidrug antibody; } A L\end{array}$ & $\begin{array}{l}\text { reatment period. } \\
\text { period } 1 \text { then switched to } \\
r \text { period } 1 \text { then switched } \\
=\text { adverse drug event. }\end{array}$ & $\begin{array}{l}e p t \rightarrow G P 2015 \rightarrow \text { eta } \\
15 \rightarrow \text { etanercept } \rightarrow\end{array}$ & $\begin{array}{l}\text { which continued } \\
\text { which continued it }\end{array}$ & $\begin{array}{l}\text { on. } \\
\text { on. }\end{array}$ & \\
\hline
\end{tabular}

reported in Table 1 and Table 2. A summary of individual study results is reported in Table 3 and Table 4, respectively.

Twenty-eight studies involving a total of 2,956 patients switched from infliximab biologic products to biosimilars were included in the review. ${ }^{20-47}$ Two of these studies were doubleblinded randomized controlled trials (RCTs). Presence of baseline ADAs was reported in 12 infliximab open-label studies. ADA development and infusion reactions were similar between open-label and double-blinded studies. Discontinuation rates for any reason, for ADEs, and for lack of efficacy were generally higher in open-label trials compared with double-blinded trials. A summary of reported discontinuation rates and ADEs for infliximab studies is reported in Table 5.

Three studies involved switching 315 patients from etanercept to a biosimilar product. ${ }^{48-50}$ Two publications evaluated different time points of the same double-blinded RCT. One study was a prospective open-label design. ${ }^{50}$ Of note, the 2 double-blinded RCTs listed in Tables 3 and 4 analyzed the same 196 patients. Results differed by the grouping of patients and in the time period collected. Griffiths et al. (2017) divided patients into 2 nonswitching and 2 switching arms. ${ }^{48}$ Switched patients followed 1 of the following algorithms: (a) those receiving a biosimilar for period 1 then switched to reference product, biosimilar, and finally reference product, which continued into extension, and (b) those receiving the reference product for period 1 then switched to biosimilar, reference product, and finally biosimilar, which continued into extension. Gerdes et al. (2017) pooled switched patients together to compare results against pooled nonswitched patients. ${ }^{49}$

\section{Discussion}

Some evidence from the comparison of biosimilar discontinuation rates supports the hypothesis that this outcome measure is highly susceptible to the nocebo effect. Median discontinuation rates of infliximab biosimilars for any reason, due to ADEs or lack of efficacy, were generally higher in open-label trials, suggesting that knowledge of a switch to a biosimilar product may have affected patient perceptions and subsequent outcomes. Etanercept biosimilar discontinuation rates for any reason were similar between study designs, but closer analysis of discontinuations due to ADEs also contradicts the theory of the nocebo effect. However, few studies were available evaluating a switch involving etanercept biosimilars. Clearer trends may be identified as additional studies with larger sample sizes are conducted.

Wide variability in the range of documented infusion and injection site reactions makes it difficult to draw a clear conclusion. In addition, the rate of etanercept biosimilar-related injection site reactions favors a trend opposing the nocebo effect. Ranges of objective ADEs, such as ADA development, were quite variable between study designs. Although hypothesized as unlikely to be susceptible to the nocebo effect, lack of reporting of baseline ADAs in double-blinded trials, coupled with relatively low reporting in open-label trials, prevented close evaluation of objective ADEs. Overall, the evidence is not sufficiently robust to clearly determine the presence of a nocebo effect during switches to a biosimilar product.

Analyses have reported biosimilars may represent up to $\$ 44$ billion in potential cost savings over a 10 -year period. ${ }^{3,6}$ Unfortunately, uptake of biosimilars in the United States has been poor, in part due to prescriber discomfort with switching patients from reference products to biosimilars. ${ }^{51}$ This review suggests that the negative expectations of patients may increase ADEs and discontinuation rates when switching to biosimilar products for infliximab and etanercept. Negative results from this phenomenon would then reinforce negative expectations of biosimilars and further hinder the possibility of biosimilar uptake in the United States. 
The Biosimilar Nocebo Effect? A Systematic Review of Double-Blinded Versus Open-Label Studies

TABLE 5 Summary of Open-Label Versus Double-Blinded Infliximab Studies ${ }^{20-47}$

\begin{tabular}{|c|c|c|c|c|c|c|}
\hline & \multicolumn{3}{|c|}{ Open-Label Studies } & \multicolumn{3}{|c|}{ Double-Blinded Studies } \\
\hline & \multicolumn{2}{|c|}{$\begin{array}{c}\text { Median (Range) } \\
\%\end{array}$} & \multirow{2}{*}{$\begin{array}{c}\begin{array}{c}\text { Number of Studies } \\
\text { Reporting Outcome }\end{array} \\
14\end{array}$} & \multicolumn{2}{|c|}{$\begin{array}{c}\text { Median (Range) } \\
\%\end{array}$} & \multirow{2}{*}{$\begin{array}{l}\begin{array}{l}\text { Number of Studies } \\
\text { Reporting Outcome }\end{array} \\
2 \\
\end{array}$} \\
\hline ADA development & 12.65 & $(2.3-65.9)$ & & 13.10 & $(12.4-13.8)$ & \\
\hline Infusion reaction & 2.85 & $(0.0-12.1)$ & 14 & 2.00 & $(2.0-2.0)$ & 1 \\
\hline Discontinuation, any & 14.70 & $(0.0-33.3)$ & 21 & 6.95 & $(6.4-7.5)$ & 2 \\
\hline Discontinuation, $\mathrm{ADE}$ & 5.60 & $(0.0-24.2)$ & 25 & 2.85 & $(2.5-3.2)$ & 2 \\
\hline Discontinuation, lack of efficacy & 6.45 & $(0.0-18.1)$ & 18 & 1.20 & $(1.2-1.2)$ & 1 \\
\hline
\end{tabular}

$A D A=$ antidrug antibody; $A D E=$ adverse drug event.

Strategies to combat the nocebo effect may be categorized as either conditioning or managing expectations of the patient and prescriber. Conditioning involves gradual introduction of the intervention or introduction of the intervention without patient knowledge. While gradual introduction may be technically feasible (e.g., dividing the total dose into part biosimilar and part reference product), this strategy is impractical and unlikely to be adopted by insurance providers. Switching patients to a biosimilar product without prescriber or patient knowledge presents several practical barriers, such as the lack of legality of biosimilar substitution without notification and the ability to identify the product prior to administration. This strategy may also be considered unethical and dishonest. ${ }^{52-54}$ Thus, managing expectations through patient empowerment may be the most viable option for mitigating the biosimilar nocebo effect.

The most obvious way to manage patient expectations of biosimilars is through education. Many surveys have indicated that prescribers do not have a strong understanding of the manufacturing process, approval requirements, or ongoing regulation of biologic and biosimilar products..$^{55,56}$ This knowledge gap likely contributes to negative expectations. Prescriber hesitancy is probably a strong factor in creating or reinforcing patients' negative expectations and could enhance the nocebo effect. Appropriate framing of the discussion regarding switching to a biosimilar may help mitigate nocebo effects. An honest discussion should focus on the positive effects (cost savings), without intentional or subconscious hints that the biosimilar product is a "knock-off" product or possibly less safe or effective. Avoiding an overly focused discussion on potential ADEs has also been suggested to help manage expectations and decrease the nocebo effect. ${ }^{52}$ The ethical implications of paternalistic nondisclosure to decrease nocebo-induced ADEs have been a controversial topic of debate that cannot be ignored. Transparency is an important principle in modern bioethics, raising the question of whether or not it is acceptable to waive our duty to inform patients in order to uphold nonmaleficence. ${ }^{57,58}$ Regardless of which approach is taken, education for providers, pharmacists, and patients will certainly be an essential foundation to mitigating the biosimilar nocebo effect.

\section{Limitations}

This review has some limitations that need to be considered. The overall number of randomized, double-blinded studies identified was quite small compared with the number of openlabel, observational studies, which makes it difficult to draw meaningful conclusions on the comparison. Comparing ADE rates across different studies may introduce many sources of bias. The patient populations in different studies varied greatly. The double-blinded trials did not include treatment of IBD, which was a large portion of the open-label trials. In addition, most data available were limited to one of the biosimilar products (CT-P13), but ADE rates may be product specific. The duration of follow-up was often short in open-label studies, which may decrease the ability to detect or report ADEs, especially those that may develop over prolonged exposure (e.g., ADA development). The frequency for monitoring of ADEs, especially ADA development, was higher in the double-blinded studies. Many of the open-label studies did not report ADA monitoring practices or only conducted ADA testing after significant adverse reactions or loss of efficacy. In addition, the definitions for ADA development and confirmation of non-transient ADAs were not clearly defined in all studies. Finally, the heterogeneous population included in the studies may have introduced bias from an unknown or unevaluated source such as previous therapies, duration of previous therapies, or disease severity.

\section{Conclusions}

Current evidence is insufficient to confirm a biosimilar nocebo effect, although higher discontinuation rates in infliximab biosimilar open-label studies support this theory. However, many limitations prevent drawing strong conclusions. Further studies are needed to evaluate the existence of a biosimilar nocebo effect. If it does indeed exist, the effects of mitigation strategies such as prescriber education and patient empowerment should be evaluated. 


\section{Authors}

JOHLEE S. ODINET, PharmD, BCPS; CHELSEA E. DAY, BS; JENNIFER L. CRUZ, PharmD, BCPS; and GREGORY A. HEINDEL, PharmD, BCPS, Department of Pharmacy, University of North Carolina Medical Center, Chapel Hill.

AUTHOR CORRESPONDENCE: Gregory A. Heindel, PharmD, BCPS, Department of Pharmacy, University of North Carolina Hospitals, 101 Manning Dr., Chapel Hill, NC 27514.

Tel.: 984.974.7752; E-mail: Gregory.Heindel@unchealth.unc.edu.

\section{DISCLOSURES}

No outside funding supported this study. The authors have no conflicts of interest to disclose.

\section{REFERENCES}

1. U.S. Food and Drug Administration. Biologics Price Competition and Innovation Act. 2009. Available at: https://www.fda.gov/downloads/Drugs/ GuidanceComplianceRegulatoryInformation/UCM216146.pdf. Accessed August 1, 2018

2. Christl L. FDA's overview of the regulatory guidance for the development and approval of biosimilar products in the U.S. Available at: https://www. fda.gov/downloads/drugs/developmentapprovalprocess/howdrugsaredevelopedandapproved/approvalapplications/therapeuticbiologicapplications/ biosimilars/ucm428732.pdf. Accessed August 1, 2018.

3. Mulcahy A, Predmore Z, Mattke S. The cost savings potential of biosimilar drugs in the United States. 2014. Available at: https://www.rand.org/content/dam/rand/pubs/perspectives/PE100/PE127/RAND_PE127.pdf. Accessed August 1, 2018

4. Sarpatwari A, Avorn J, Kesselheim AS. Progress and hurdles for follow-on biologics. N Engl J Med. 2015;372(25):2380-82

5. Aladul MI, Fitzpatrick RW, Chapman SR. Impact of infliximab and etanercept biosimilars on biological disease-modifying antirheumatic drugs utilisation and NHS budget in the UK. BioDrugs. 2017;31(6):533-44.

6. Oskouei S. Following the biosimilar breadcrumbs: when health systems and manufacturers approach forks in the road. J Manag Car Spec Pharm. 2017;23(12):1245-48. Available at: https://www.jmcp.org/doi/10.18553/ jmcp.2017.23.12.1245.

7. Chapman SR, Fitzpatrick RW, Aladul MI. Knowledge, attitude and practice of healthcare professionals towards infliximab and insulin glargine biosimilars: results of a UK web-based survey. BMJ Open. 2017;7(6):e016730.

8. Waller J, Sullivan E, Piercy J, Black CM, Kachroo S. Assessing physician and patient acceptance of infliximab biosimilars in rheumatoid arthritis, ankylosing spondyloarthritis and psoriatic arthritis across Germany. Patient Prefer Adherence. 2017;11:519-30.

9. Rezk M, Pieper B. Treatment outcomes with biosimilars: be aware of the nocebo effect. Rheumatol Ther. 2017;4(2):209-18.

10. Tweehuysen L, van den Bemt BJF, van Ingen IL, et al. Subjective complaints as the main reason for biosimilar discontinuation after open-label transition from reference infliximab to biosimilar infliximab. Arthritis Rheumatol. 2018;70(1):60-68.

11. Barsky A. The iatrogenic potential of the physician's words. JAMA. 2017;318(24):2425-26

12. Webster RK, Weinman J, Rubin GJ. A systematic review of factors that contribute to nocebo effects. Health Psychol. 2016;35(12):1334-55.
13. Gupta A, Thompson D, Whitehouse A, et al. Adverse events associated with unblinded, but not with blinded, statin therapy in the AngloScandinavian Cardiac Outcomes Trial-Lipid-Lowering Arm (ASCOT-LLA): a randomized double-blind placebo-controlled trial and its non-randomised non-blind extension phase. Lancet. 2017;389(10088):2473-81.

14. Mondaini N, Gontero P, Giubilei G, et al. Finasteride $5 \mathrm{mg}$ and sexual side effects: how many of these are related to a nocebo phenomenon? J Sex Med. 2007;4(6):1708-12.

15. Silvestri A, Galetta P, Cerquetani E, et al. Report of erectile dysfunction after therapy with beta-blockers is related to patient knowledge of side effects and is reversed by placebo. Eur Heart J. 2003;24(21):1928-32.

16. Mills L, Dar-Nimrod I, Colaqiuri B. Effect of genetic information and information about caffeine content on caffeine withdrawal symptoms. Sci Rep. 2017;7(1):8407.

17. Zaccara G, Giovannelli F, Giorgi FS, Franco V, Gasparini S. Analysis of nocebo effects of antiepileptic drugs across different conditions. J Neurol. 2016;263(7):1274-79

18. Webster RK, Weinman J, Rubin GJ. How does the side-effect information in patient information leaflets influence peoples' side-effect expectations? A cross-sectional national survey of 18- to 65-year-olds in England. Health Expect. 2017;20(6):1411-20

19. Boone NW, Lu L, Romberg-Camps MJ, et al. The nocebo effect challenges the non-medical infliximab switch in practice. Eur J Clin Pharmacol. 2018;74(5):655-61.

20. Smolen JS, Choe JY, Prodanovic N, et al. Safety, immunogenicity and efficacy after switching from reference infliximab to biosimilar SB2 compared with continuing reference infliximab and SB2 in patients with rheumatoid arthritis: results of a randomised, double-blind, phase III transition study. Ann Rheum Dis. 2018;77(2):234-40.

21. Jørgensen KK, Olsen IC, Goll GL, et al. Switching from originator infliximab to biosimilar CT-P13 compared with maintained treatment with originator infliximab (NOR-SWITCH): a 52-week, randomised, double-blind, non-inferiority trial. Lancet. 2017;389(10086):2304-16.

22. Park W, Yoo DH, Miranda P, et al. Efficacy and safety of switching from reference infliximab to CT-P13 compared with maintenance of CT-P13 in ankylosing spondylitis: 102-week data from the PLANETAS extension study. Ann Rheum Dis. 2017;76(2):346-54.

23. Jung YS, Park DI, Kim YH, et al. Efficacy and safety of CT-P13, a biosimilar of infliximab, in patients with inflammatory bowel disease: a retrospective multicenter study. J Gastroenterol Hepatol. 2015;30(12):1705-12.

24. Kang YS, Moon HH, Lee SE, Lim YJ, Kang HW. Clinical experience of the use of CT-P13, a biosimilar to infliximab in patients with inflammatory bowel disease: a case series. Dig Dis Sci. 2015;60(4):951-56.

25. Park SH, Kim YH, Lee JH, et al. Post-marketing study of biosimilar infliximab (CT-P13) to evaluate its safety and efficacy in Korea. Expert Rev Gastroenterol Hepatol. 2015;9(Suppl 1):35-44.

26. Hlavaty T, Krajcovicova A, Sturdik I, et al. Biosimilar infliximab CT-P13 treatment in patients with inflammatory bowel diseases-a one-year, singlecentre retrospective study. Gastroenterologie a Hepatologie. 2016;70(1):27-36.

27. Schmitz E, Boekema P, Straathof J, et al. Switching from infliximab innovator to biosimilar in patients with inflammatory bowel disease: a 12-month multicentre observational prospective cohort study. Aliment Pharmacol Ther. 2018;47(3):356-63.

28. Eberl A, Huoponen S, Pahikkala T, Blom M, Arkkila P, Sipponen T. Switching maintenance infliximab therapy to biosimilar infliximab in inflammatory bowel disease patients. Scand J Gastroenterol. 2017;52(12):1348-53

29. Fiorino G, Correale C, Radice S, et al. Letter: immunogenicity of infliximab originator vs. CT-P13 in IBD patients. Aliment Pharmacol Ther. 2017:46(9):903-05. 
30. Smits L, Grelack A, Derikx L, et al. Long-term clinical outcomes after switching from Remicade to biosimilar CT-P13 in inflammatory bowel disease. Dig Dis Sci. 2017;62(11):3117-22

31. Argüelles-Arias F, Guerra Veloz M, Perea Amarillo R, et al. Switching from reference infliximab to CT-P13 in patients with inflammatory bowel disease: 12 months results. Eur J Gastroenterol Hepatol. 2017;29(11):1290-95.

32. Razanskaite V, Bettey M, Downey L, et al. Biosimilar infliximab in inflammatory bowel disease: outcomes of a managed switching programme. J Crohns Colitis. 2017;11(6):690-96.

33. Buer L, Moum B, Cvancarova M, Warren D, Medhus A, Høivik M. Switching from Remicade to Remsima is well tolerated and feasible: a prospective, open-label study. J Crohns Colitis. 2017;11(3):297-304.

34. Fiorino G, Manetti N, Armuzzi A, et al. The PROSIT-BIO cohort: a prospective observational study of patients with inflammatory bowel disease treated with infliximab biosimilar. Inflamm Bowel Dis. 2017;23(2):233-43.

35. Kolar M, Duricova D, Bortlik M, et al. Infliximab biosimilar (Remsima) in therapy of inflammatory bowel diseases patients: experience from one tertiary inflammatory bowel diseases centre. Dig Dis. 2017;35(1-2):91-100.

36. Smits L, Derikx L, de Jong D, et al. Clinical outcomes following a switch from Remicade to the biosimilar CT-P13 in inflammatory bowel disease patients: a prospective observational cohort study. J Crohns Colitis. 2016;10(11):1287-93.

37. Kang B, Lee Y, Lee K, Choi YO, Choe YH. Long-term outcomes after switching to CT-P13 in pediatric-onset inflammatory bowel disease: a single-center prospective observational study. Inflamm Bowel Dis. 2018;24(3):607-16.

38. Nikiphorou E, Kautiainen H, Hannonen P, et al. Clinical effectiveness of CT-P13 (infliximab biosimilar) used as a switch from Remicade (infliximab) in patients with established rheumatic disease. Expert Opin Biol Ther. 2015;15(12):1677-83.

39. Tanaka Y, Yamanaka H, Takeuchi T, et al. Safety and efficacy of CT-P13 in Japanese patients with rheumatoid arthritis in an extension phase or after switching from infliximab. Mod Rheumatol. 2017;27(2):237-245.

40. Yoo DH, Prodanovic N, Jaworski J, et al. Efficacy and safety of CT-P13 (biosimilar infliximab) in patients with rheumatoid arthritis: comparison between switching from reference infliximab to CT-P13 and continuing CT-P13 in the PLANETRA extension study. Ann Rheum Dis. 2017;76(2):355-63.

41. Glintborg B, Sørensen IJ, Loft A, et al. A nationwide non-medical switch from originator infliximab to biosimilar CT-P13 in 802 patients with inflammatory arthritis: 1-year clinical outcomes from the DANBIO registry. Ann Rheum Dis. 2017;76(8):1426-31

42. Benucci M, Gobbi FL, Bandinelli F, et al. Safety, efficacy and immunogenicity of switching from innovator to biosimilar infliximab in patients with spondyloarthritis: a 6-month real-life observational study. Immunol Res. 2017;65(1):419-22

43. Vergara-Dangond C, Sáez Belló M, Climente Martí M, Llopis Salvia P, Alegre-Sancho JJ. Effectiveness and safety of switching from innovator infliximab to biosimilar CT-P13 in inflammatory rheumatic diseases: a realworld case study. Drugs R D. 2017;17(3):481-85.
44. Holroyd CR, Parker L, Bennett S. Switching to biosimilar infliximab: real world data in patients with severe inflammatory arthritis. Clin Exp Rheumatol. 2018;36(1):171-72.

45. Avouac J, Moltó A, Abitbol V, et al. Systematic switch from innovator infliximab to biosimilar infliximab in inflammatory chronic diseases in daily clinical practice: the experience of Cochin University Hospital, Paris, France. Semin Arthritis Rheum. 2018;47(5):741-48.

46. Schmitz E, Benoy-De Keuster S, Meier A, et al. Therapeutic drug monitoring (TDM) as a tool in the switch from infliximab innovator to biosimilar in rheumatic patients: results of a 12-month observational prospective cohort study. Clin Rheumatol. 2017;36(9):2129-34

47. Abdalla A, Byrne N, Conway R, et al. Long-term safety and efficacy of biosimilar infliximab among patients with inflammatory arthritis switched from reference product. Open Access Rheumatol. 2017;9:29-35.

48. Griffiths C, Thaci D, Gerdes S, et al. The EGALITY study: a confirmatory, randomized, double-blind study comparing the efficacy, safety and immunogenicity of GP2015, a proposed etanercept biosimilar, vs. the originator product in patients with moderate-to-severe chronic plaque-type psoriasis. Br J Dermatol. 2017;176(4):928-38.

49. Gerdes S, Thaçi D, Griffiths C, et al. Multiple switches between GP2015, an etanercept biosimilar, with originator product do not impact efficacy, safety and immunogenicity in patients with chronic plaque-type psoriasis: 30-week results from the phase 3, confirmatory EGALITY study. J Eur Acad Dermatol Venereol. 2018;32(3):420-27.

50. Emery P, Vencovský J, Sylwestrzak A, et al. Long-term efficacy and safety in patients with rheumatoid arthritis continuing on SB4 or switching from reference etanercept to SB4. Ann Rheum Dis. 2017;76(12):1986-91.

51. Hakim A, Ross JS. Obstacles to the adoption of biosimilars for chronic diseases. JAMA. 2017;317(21):2163-64.

52. Chavarria V, Vian J, Pereira C, et al. The placebo and nocebo phenomena: their clinical management and impact on treatment outcomes. Clin Ther. 2017:39:477-86.

53. Data-Franco J, Berk M. The nocebo effect: a clinician's guide. Aust N Z J Psychiatry. 2013;47:617-23.

54. Bartels DJ, Van Laarhoven AI, Stroo M, et al. Minimizing nocebo effects by conditioning with verbal suggestion: a randomized clinical trial in healthy humans. PLoS ONE. 2017;12(9):e0182959.

55. Pasina L, Casadei G, Nobili A. A survey among hospital specialists and pharmacists about biosimilars. Eur J Intern Med. 2016;35:e31-e33.

56. Cohen H, Beydoun D, Chien D, et al. Awareness, knowledge, and perceptions of biosimilars among specialty physicians. Adv Ther. 2017;33(12):2160-72.

57. Schoene-Seifert B. Beware of nocebo-paternalism: pitfalls of tailored nondisclosure. Am J Bioeth. 2017;17(6):56-58.

58. Fortunato JT, Wasserman JA, Menkes DL. Nonmaleficence, nondisclosure, and nocebo: response to open peer commentaries. Am J Bioeth. 2017;17(7):W4-W5. 